\title{
School Mapping in the Light of Education Reforms in Pakistan
}

\author{
Muhammad Majid Sabir* \\ Qurtuba University of Science \& Information Technology, Peshawar, Pakistan \\ *Corresponding author: mmajidsabir@yahoo.com \\ Received April 09, 2013; Revised May 06, 2013; Accepted July 10, 2013
}

\begin{abstract}
The main focus of this qualitative study is to address the prevailing situation of school mapping at provincial level of Khyber-Pakhtunkhwa and its twenty four districts to diagnose the major factors of the reluctances by the educational planners and more specifically to ascertain why its importance is not realized in Educational Management Information System (EMIS). Data were collected by means of interviews with provincial EMIS managers and Executive District Officers; and by means of telephone conversations from the rest of eight districts. The uniqueness of this study is that the results show that planners at Provincial and District levels are aware of the importance of school-mapping although vital efforts have not been made to use it as an instrument in planning.
\end{abstract}

Keywords: qualitative, school mapping, education management information system (EMIS), geographic information system (GIS), national Education management information system (NEMIS)

Cite This Article: Muhammad Majid Sabir, "School Mapping in the Light of Education Reforms in Pakistan.” American Journal of Educational Research 1, no. 8 (2013): 279-282. doi: 10.12691/education-1-8-2.

\section{Introduction}

Many reforms have been introduced in school sector by the Government of Pakistan in which the major attention was given to the management of schools. According to Mathur (2005), management depends on controlling the available resources to achieve the desired target. Even most of the managers are not aware of effective planning or have poor understanding [1].

The most important aspect of the planning in school sector is related to the location of the institutions. The process of location planning in education is called "School Mapping'. It involves the process of identifying the communities and places where educational facilities proposed in the PLAN are to be located. It requires systematic effort designed to locate educational facilities in such a manner that targeted age-groups of the population are able to use facilities to their maximum advantage [2].

In recent years this phase is identified by the term "school-mapping". It is an activity as indicated by the gerund "mapping" and not to be confused with "school map. The original term ("carte scolaire" in French) and the concept has been widely used in French-and Spanishspeaking countries [3].

School Mapping is the dynamic process of identifying logically and systematically the communities and sites where educational facilities provided in the plan are to be located. As educational facilities have been synonymous with schools, the terms have been rather narrowly conceived as school-mapping [4]. So, during the last decade, educational planners are engaged in widening the concept of school-mapping to one of the educational mapping.

This does not mean that one concept eliminates the other. For all practical purposes, school-mapping and educational mapping will remain distinct activities each with its own utility value, purpose and direction. The process of investigation for school-mapping for the school-mapping is the same as for educational mapping and its final result is manifold [5].

- It will produce a catalogue of educational needs (or learning needs) of the society as a whole;

- It will produce an inventory of available educational facilities;

- It will show which of the facilities are utilized or under-utilized;

- It will provide guidelines as to how the available facilities can be recognized by redistribution of either the facilities themselves or their users; and

- It will enable the new facilities to be provided where they can be utilized to the highest advantage.

But the main difference is that often narrow objectives and aims are concentrated at identifying location for the construction of school, classrooms, laboratories etc.

Evaluation of use-efficiency, reorganisation and redistribution of facilities and maximisation of use continue to be the next outcome of the school-mapping exercise [6].

\subsection{School Mapping Activity}

The last phase in the planning process, when the physical facilities that are to be provided under the plan are actually located or sited; that is, to decide where (in what community or geographical area) the school, 
laboratories, workshops and such other educational facilities are to be built or provided. It is suggested to undertake a detailed school mapping activity in each of the district covering school and non-school based data in doing this activity, the present stock of data at the EMIS center or cell should be considered to avoid duplication.

Establish close linkage with the other government agencies like ministry of Defence, Natural Resources or Environment, Census, planning Office and others to ensure that the requirements of school mapping as a tool for the in depth analysis of the existing situation of the district can be fully addressed. This will also build- up and update the present stock of data of the EMIS centres and cells [7].

\subsection{Scope of School Mapping}

With the recent development in non-formal education in areas such as literacy programs, post-literacy courses, vocations training and adult education, school mapping should cover not only the distribution of formal educational facilities but also the non-formal educational facilities [8].

The process of school mapping covers the following specific areas for expansion and improvement of facilities:

1. Rationalisation of existing facilities by:

- shifting, closure or amalgamation of institutions;

- optimum utilisation of teaching and non-teaching staff;

- optimum utilisation of buildings, equipment's, furniture, etc.

2. Provision of new or additional facilities by:

- Opening of new schools or upgrading of existing ones;

- Providing additional teaching and non-teaching staff;

- Providing new or additional buildings, furniture and equipment in institutions.

Thus, school mapping has the double function of securing greater equality of education opportunities and at the same time of rationalizing the use of existing facilities in an effort to optimize the limited material and manpower resources.

\section{Methodology}

The assessment was only confined to school level. In assessing the extent of the school mapping activities the province was divided into three levels i.e. Secretariat, Directorate at provincial level, and office of the Executive District Officers at district level. Some basic questions included in the interview were asked to respondents such as: Chief Planning Officer, Provincial Director, Executive District Officers of Education and the EMIS staff both at provincial and district level. The major area of the questions were about the activities related to school mapping, utilisation of EMIS for school mapping, data asked in school mapping, processing of the data and users of these data.

\section{Results and Discussion}

It was found out that the EMIS operation is contributing negligibly to the planning and the school mapping activities and this situation is prevailing at the both provincial and district levels. The proformas used for collecting data basically capture enrolment of students, profile of teachers and very limited information about the school facilities. Assuming that these data would be utilized for school mapping, these are very inadequate to characterize the schools and their environment since it does not contain non-school based data such as socioeconomic and demographic which are essential in school mapping activities.

Apparently, there are no conscious efforts at the district level. The absence of this exercise considering its importance could be attributed to some reasons: lack of knowledge of the concerned officials to carry out the activity, the absence of the clear-cut policy direction on what, how and when this activity should be undertaken, and no available resources in terms of manpower, infrastructure, and facilities essential to the conduct school mapping. It was also noted that the up gradation of schools are made using some standards which were derived from EMIS data. However, certain decisions were to locate cite and what schools should be upgraded are more often a political rather than technical based decision.

The establishment and operationalisation of the EMIS centre as early as 1990 in the province has produced education statistics on public schools. It has not attempted to convert its system into geographic information system (GIS) and has not conducted school mapping of the province nor of district in spite of the presence of EMIS cell in each of its districts.

The computer based EMIS has provided a network system in the development and production of digitized Info maps using GIS. The installation of GIS facilitates the production of Info maps about the districts in locating and characterizing different type of schools. It is evident in the database of the GIS info maps which do not contain socio-economic and demographic data about the district or the village being characterized or diagnosed. The computer programmers and other staff in the EMIS office are not conversant about what school mapping is and how it relates to the production of a comprehensive and usable info maps. EMIS and GIS are not widely disseminated to the data providers and intended users.

The assistance provided by the international funding agencies has immensely contributed to the development and operationalisation of a computerized EMIS and GIS. The EMIS proforma which is the main source of basic education data are also input to the GIS which produces digitized district maps showing the school network and database of each school. The GIS has the capacity to locate and characterize individual school according to socio-economic, demographic, geographic profile and other factors.

This capacity is not however maximized due to inadequate data and information inputs which can be a result of a detailed school mapping exercise in the province. The present outputs are not sufficient to determine more critical analysis of the educational development of a district in terms of educational deprivation, school location planning, resource allocation and other important decisions and policy action.

\section{Recommendations}


In the light of this brief assessment of the prevailing condition on school mapping at provincial level and twenty four districts of province, the following recommendations are offered to improve the school mapping activities.

\subsection{Inventory of Resources}

All the districts should conduct an inventory of its existing resources in terms of manpower, hardware, software, databanks, systems and procedures in managing data and information. The results of this inventory or configuration will determine the gaps, shortfalls, shortcomings of the EMIS in meeting its current and future demands and requirements.

\subsection{Sessions with Data Users}

The sessions regarding data identification needs and requirements may be conducted with the potential data users and providers such as education officials, Government authorities, school heads, computer programmers, international agencies and non-government organisations. This will ensure that the relevant data needs and requirements of these concerned persons can be captured in the data collection proformas. The session will also provide an opportunity for the users and providers to discuss the viability of obtaining these data and also its usability.

\subsection{School Mapping Activity}

The detailed school mapping activity may be undertaken in each of the district covering school and nonschool based data. In doing this activity, the present stock of data at the EMIS centre or cell should be considered to avoid duplication. Establish close linkage with the other Government agencies like Ministry of Defence, Natural Resources or environment, Census, Planning office and others to ensure that the requirements of school mapping as a tool for the in-depth analysis of the existing situation of the district can be fully addressed. This will also buildup and update the present stock of data of EMIS centres and cells.

\subsection{Training on School Mapping}

Conduct a district wide training on school mapping to all those who will be involved in the school mapping activity so that they can fully understand and appreciate the use and importance of school mapping. It is important that the participants should be informed of the expected outputs of this exercise since this will not be an annual regular activity unlike the EMIS data collection activity which is regularly being undertaken three months after the opening or start of the academic year.

\subsection{Geographic Information System}

For districts with an established GIS in producing info maps of the district, the data generated from the school mapping be used as basis to improve its digitized maps by incorporating the new data elements this will also enhance the usability of these maps for purposes of planning, policy and decision-making .however, hard copies of these maps should be disseminated to the potential users for their information and use. Hard or printed copies for the major info maps of the province or the district should be made accessible and visible for wider advocacy, dissemination and better appreciation. These should not be kept in the computer alone.

\subsection{Collaboration}

Most of the districts do not have the capability and resources to use GIS, collaboration or agreement may be forged with the province which has the existing facilities to process for them their school mapping data and information.

\subsection{Individual School Database}

Before embarking or planning to acquire hardware and software (GIS) for the school mapping, it is necessary that the individual school database should have been firmed up for comprehensive characterisation of the school, better location of possible interventions and rationale allocation of resources.

\subsection{Issues to be Addressed}

As we moved on to the next millennium, new challenges and demands will come along the way in pursuit of development and in attaining the envisioned goals of the country. Resources are getting scarce and limited that wastage of these resources should be of utmost concern [9]. The number of student population is increasing at a pace which the government may not be able to match its needs and requirements. Since development and progress do not occur or take place at the same level and assumed that all the districts or school suffers educational poverty in varying degrees, it is necessary that any attempt to provide interventions and opportunities to stakeholders should be made according to priorities and seriousness of needs.

1. There is a need to review and revise existing policies, system and procedures to effect a more rational approach to upgrading schools from one level to another, well defined scheme for allocation of resources and better location of new schools.

2. There is a need to network all the districts in a province in terms of internet linkage so that the flow and sharing of data information would be more expeditious and timely.

3. There is a need for the private schools to be included in school mapping activity for a holistic, balanced, complete and comprehensive assessment of the country's educational system. Evolve a policy to integrate public and private school system into one in terms of curriculum, standards and evaluation of student achievement.

4. All provincial EMIS centres may be linked through internet to the NEMIS. This will establish well defined common data elements; synchronize data collection and processing system using common computer language; faster sharing of information; clearer and meaningful analysis of the performance of the country's educational system.

5. GIS may be extensively used in producing well characterized, detailed and comprehensive district and school maps. A stronger or more powerful server 
and other equipment may be needed to upgrade and build its present capacities and capabilities.

6 . The education officials, teachers, students, parents and leaders may be well informed about the real situation of education at various levels in different areas of the country.

\section{References}

[1] Sabir and Sadaf. Managerial Training Needs Assessment of Heads of Secodary Schools: Bulletin of Education and Research, 33(2) 2011.

[2] Kaufman, R. and Herman, J. Educational Planning: Strategic, Tactical, and Operational. Lanhalm MD: Rowman \& Littlefield Education. 2002.
[3] Villanueva, C.C. Training Manual on the strengthening of EMIS and the implementation on the conduct of a National Education Survey. Dhaka: BANBEIS. 1999.

[4] Singhal, A. Education and Social Change. New Jersey: Lawrence Erlbaum Associates. 2004

[5] Psacharopoulos, G. and Woodhall, M. Education for Development. New York: Oxford University Press USA. 2001.

[6] Welch, A.R. Third World Education: Quality and Equality. New York: Garland. 2000.

[7] Jchesswas. Basic Data needed for Educational Planning, London: Evans Bros. 1967.

[8] UNESCO. IIEP. Advance Course in Educational Planning and Management Training Materials. Paris, France. 1983.

[9] Dennis, A.R. Planning Education Reforms in Developing Countries, Durham NC: Duke University Press. 1990. 